If we talk about science, then in the political vocabulary of other countries you can find two versions of the translation of the term public diplomacy - "public diplomacy" and "public diplomacy". This is certain confusion, because these concepts cannot be equated. The fact is that the word "public" is translated into other languages as "social", "civil", "popular"18. Meanwhile, civil (people's) diplomacy is an unofficial activity of individuals and legal entities, NGOs, various institutions and movements that are not directly dependent on the government, but nevertheless can help improve interstate relations and establish cooperation between peoples.

Therefore, by public diplomacy we mean diplomacy at the level of non-governmental organizations, the expert community, while public diplomacy includes a wider range of activities. In this regard, the means by which one state seeks to influence the audience of another is correctly designated by the term "public diplomacy", because by it we mean the system of interaction with foreign public of both governmental and non-governmental entities. Consequently, the concept of public diplomacy is only one of the areas of public diplomacy, but by no means a synonym.

Thus, public diplomacy is a generalized concept denoting the activities of various actors, both governmental and non-governmental, which is designed to explain to the foreign public the country's foreign policy and to encourage a particular foreign state to make its foreign policy decisions in a way that is beneficial to these actors. If we talk about the relationship between public diplomacy and soft power, then in this case, these two concepts cannot be equated with each other, because public diplomacy is just one of the tools of soft power. In turn, the forms of public diplomacy include: public, cultural, digital diplomacy, etc. They predetermine its entire need for use in foreign policy by the states of the world that are trying to influence the "hearts and minds" of people.

УДК 34.05

ГРНТИ 10.91

ОБЩАЯ ХАРАКТЕРИСТИКА СМЕШАННОЙ ПРАВОВОЙ СИСТЕМЫ РЕСПУБЛИКИ ИНДИЯ DOI: $10.31618 /$ ESU.2413-9335.2020.6.70.566

Пчелинцева Валерия Викторовна

Магистрант международно-правового факультета МГИМО (У) МИД России 2. Москва

\title{
GENERAL OVERVIEW OF THE MIXED LEGAL SYSTEM OF THE REPUBLIC OF INDIA
}

\section{АННОТАЦИЯ}

В статье рассматриваются особенности правовой системы Республики Индия как одной из смешанных правовых систем современности, а также обосновывается точка зрения о том, что данную правовую систему отличает сочетание черт англосаксонской, романо-германской, индусской и мусульманской правовых семей. Исследуется механизм применения на территории Индии систем религиозных и обычных норм, не признаваемых в качестве самостоятельных правовых систем современной сравнительно-правовой наукой. Обозначаются некоторые вопросы, касающиеся характеристики индийской правовой системы, которые требуют дальнейшей научной разработки.

\section{ABSTRACT}

The article contains the analysis of the key features of the legal system of the Republic of India as a contemporary mixed legal system. It is argued that the Indian legal system shows a combination of traits of the common law, continental, Hindu and Muslim legal systems. The mechanism of application of the systems of religious and customary norms that are not qualified as separate legal systems according to the modern comparative law doctrine is explored as well. The questions that require further investigation are announced.

Ключевые слова: правовая система Республики Индия, правовая система Индии, смешанные правовые системы, индусское право, мусульманское право, индийское право, юридическая география

Key words: Indian legal system, legal system of the Republic of India, mixed legal systems, Hindu law, Muslim law, Indian law, legal map of the world

Правовая система Республики Индия является уникальным образцом современной смешанной правовой системы. Ее отличает сочетание характеристик англо-американской, романогерманской, индусской и мусульманской правовых семей, а также таких систем религиозных и обычных норм, которые не признаются в качестве самостоятельных правовых систем современной компаративистикой.
Изучение правовой системы Республики Индия представляется актуальным для целей юридической географии, а также теории сравнительного правоведения, в частности учения о смешанных правовых системах. Оно также способствует формированию представления о правовых механизмах применения религиозных норм в современных светских государствах. 
Научная новизна данного исследования состоит во всестороннем изучении тех правовых систем и традиций, основные черты которых проявляются в индийском праве в настоящее время, a также в выявлении некоторых вопросов, касающихся характеристики индийской правовой системы, которые требуют дальнейшей научной разработки.

Для целей исследования правовыми системами считаются правопорядки отдельных государств, а также признанные современной сравнительно-правовой доктриной иные взаимосвязанные и согласованные правовые средства регулирования общественных отношений (например, религиозные правовые системы), а правовой семьей - совокупность правовых систем, история формирования и основные черты которых являются в существенной степени схожими. Характеристика правовых систем и семей осуществляется путем сопоставления норм позитивного права, особенностей правосознания и правовой культуры субъектов.

I. Англо-американское право как основа современной правовой системь Республики Индия

Влияние англосаксонской правовой традиции на формирование современного индийского права трудно переоценить. Следует последовательно изучить проявление черт англо-американского права (1) в форме государства и системе органов государственной власти Индии; (2) в системе источников и (3) структуре современного индийского права.

(1) Форма государства и система органов государственной власти

Государственное управление Британской Индией характеризуется последовательной централизацией с передачей Британской империи полномочий, которые до того осуществлялись ОстИндской компанией, и децентрализацией власти, в ходе которой правотворческие и правоприменительные функции постепенно передавались местным служащим и должностным лицам. Из конституционной истории Индии известно [2], что в период с 1773 по 1853 год метрополией была учреждена посредством законодательных актов система государственных органов Британской Индии с учетом принципа разделения законодательной, исполнительной и судебной власти. Законом об управлении Индией 1858 года управление данной территорией было поставлено под строгий контроль Короны. Тогда управление осуществлялось в основном представителями Британской империи. Наконец, с 1861 по 1935 год осуществлялась постепенная децентрализация власти, в ходе которой в исполнении полномочий и функций органов государственной власти стало принимать участие преимущественно местное население Индии. Последними актами метрополии об управлении Британской Индией являются Закон об управлении Индией 1935 года и Закон о независимости Британской Индии 1947 года.
Созданная Британской империей система управления оказала существенное влияние на конституционный строй и правовые институты современной Индийской парламентской республики. При анализе системы органов государственной власти Индии и системы органов государственной власти Великобритании выявляется значительное сходство в порядке формирования, формах взаимодействия и ответственности законодательных и исполнительных органов, вплоть до таких отличительных черт, как включение главы государства в состав Парламента (предусмотрено статьей 79 Конституции Индии 1950 года). При этом нельзя не отметить, что два государства отличаются по форме правления и форме территориального устройства (Великобритания унитарная монархия, Индия - федеративная республика).

С другой стороны, представляется, что правовой режим взаимодействия между главой государства и органами государственной власти Республики Индия, в том числе института импичмента, схоже с правовым регулированием статуса главы государства в государствах англоамериканской правовой семьи с республиканской формой правления.

Судебная система Индии не в меньшей степени проявляет черты англо-американской правовой семьи. Хотя в ней и наблюдается специализация судебных органов (на территории Индии функционируют специализированные суды по торговым, налоговым, корпоративным делам и прочие), формирования отдельных ветвей судебной власти не наблюдается. Верховный суд Индии является высшей инстанцией, в которой осуществляется обжалование решений в разных областях права, а также конституционный контроль законодательных актов в соответствии со ст. 32 Конституции Индии.

Bce вышеизложенное подтверждает существенное влияние англосаксонской традиции на формирование системы органов управления и разделения властей в Республике Индия. Индия

(2) Система источников права Республики

Система источников индийского права включает законы, акты делегированного законодательства и подзаконные акты, в том числе прецеденты. [6] На территории Индии также подлежат применению религиозные нормы индусского и мусульманского права и обычные нормы. Представляется уместным более подробно охарактеризовать делегированное законодательство и прецедентное право Республики Индия.

Распространенная практика принятия актов делегированного законодательства является отличительной чертой англо-американской правовой семьи. В Республике Индия акты делегированного законодательства принимаются на основании статьи 312 Конституции 1950 года, а также актов ее толкования органами судебной 
власти. Так, в решении по делу D. S. Gerewal v. State of Punjab Верховный суд Индии постановил, что практика передачи парламентом нормотворческих полномочий органам исполнительной власти не противоречит основному закону государства.

Как и в государствах англосаксонской правовой семьи, в Индии источником правовых норм признается прецедент. Структура индийского судебного прецедента совпадает со структурой прецедента, принятой в государствах англоамериканского права (ratio decidendi и obiter dictum). При этом в Индии сфера применения англосаксонского правового принципа stare decisis, обосновывающего применение норм прецедентного права, у́же, чем в Великобритании или США. Только решения Верховного суда Индии и Высоких судов обладают обязательной силой для судов общей юрисдикции. Решения Высокого суда могут играть роль убеждающего прецедента в других Высоких судах и подчиненных им судебных органах. Решения, вынесенные в рамках системы специализированных судов, являются обязательными для таких судов, но не для судов с иной специализацией или судов общей юрисдикции.

(3) Система права Республики Индия: принципьл, отрасли, институтьл

Как и правовым системам, входящим в англоамериканскую правовую семью, правовой системе Республики Индия не свойственно деление права на публичное и частное. В индийской научной доктрине лишь недавно начало формироваться представление об отдельных отраслях права и законодательства. С другой стороны, индийское право различает средства правовой защиты, предоставляемые по общему праву и по справедливости. Интересно отметить, что нормы права справедливости в Индии были кодифицированы сначала британским парламентом в 1877 году, а после парламентом независимой Индии в 1963 году, когда был принят новый Закон об исполнении в натуре.

Помимо уже упомянутого принципа stare decisis стоит рассмотреть иные общие принципы права, свойственные как правопорядкам стран англо-американской правовой семьи, так и правовой системе Республики Индия. В соответствии с Конституцией и практикой Верховного суда Индии (решение по делу Chief Settlement Commr, Punjab v. Om Prakash) принцип верховенства права (rule of law) является одним из фундаментальных положений основного закона государства (element of the basic structure of the Constitution). Такие положения не могут быть изменены или упразднены, в том числе путем внесения изменений в Конституцию. Выделение таких фундаментальных норм является отличительной чертой конституционного права Индии.

В судебной практике и правовой доктрине также признается важная роль англосаксонского правового принципа континуитета (continuity) как в отношении индийской правовой системы в целом, так и в отношении прецедентного права Республики. [7, с. 142, 243]

В индийском праве встречается достаточно много присущих странам англо-американской правовой семьи институтов материального и процессуального права. Среди первых особенно примечательны доверительная собственность (траст), которая регулируется Законом о трасте 1882 года, а также институты совместной и общей собственности, которые регулируются Законом о передаче имущества 1882 года. Правовой статус имущества, а также права и обязанности лиц, обладающих разного вида правами на имущество, уточняется в нормативных судебных актах.

Помимо рассмотренных выше институтов делегированного законодательства и прецедента, следует рассмотреть процессуальный институт показаний, основанных на слухах (hearsay evidence). Данный вид доказательства регулируется статьей 60 индийского Закона о доказательствах 1872 года, согласно которой показания, основанные на слухах, признаются недопустимыми, что схоже с регулированием данного института в странах англо-американского права.

При этом в отличие от стран англосаксонской правовой семьи в Индии был практически полностью упразднен институт присяжных заседателей в уголовном и гражданском процессе.

II. Историческое влияние $u$ современное проявление в правовой системе Индии черт романо-германской (континентальной) правовой семьи

В отечественной литературе по компаративистике редко указывается на характеристики романо-германской правовой традиции, свойственные правовой системе Республики Индия. Тем не менее, историкосравнительное исследование континентального и индийского права позволяет обнаружить определенные схожие черты этих правопорядков. В качестве таковых в данном разделе рассмотрены (1) история применения континентальных правовых доктрин; (2) кодификация норм публичного и частного права; (3) выделение и развитие отраслей права и законодательства на примере административного права.

(1) История и современное применение романских правовых доктрин

В середине XVI века началась португальская колонизация индийских царств. Данный процесс сопровождался распространением на территорию колоний действия норм португальского права. Однако когда власть над территорией индийских колоний перешла к Франции и после - к Англии, а в 1672 году была учреждена новая судебная система, правоприменительную деятельность вплоть до 1682 года осуществляли юристы, обладавшие квалификацией в науках о романских правовых системах.

В научной литературе высказываются разные мнения относительно последующего развития и применения доктрин континентального права. Так, при рассмотрении концепции «правосудия, 
справедливости и добросовестности» (justice, equity and good conscience), заимствованной из общего права Британии, В.С. Дешпанди утверждает, что она применялась судами исключительно в духе англо-американской правовой традиции. [1, с. 5] Однако К.М. Шарма указывает на частые случаи обращения к римской, нидерландской и французской правовой доктрине в процессе толкования и практического применения данной концепции. [8, с. 8-11]

По результатам рассмотрения истории и современного применения правовых доктрин стран романо-германской правовой семьи, К.М. Шарма приходит к выводу о том, что некоторые концепции сохраняются в правовой системе Индии до наших дней, в связи с чем более глубокое изучение индийскими юристами основ континентального права имеет особое значение для надлежащего применения правовых норм. [8, с. 38-39]

Освещенный в данной части статьи вопрос представляется недостаточно проработанным как в отечественной, так и в зарубежной компаративистской литературе.

(2) Кодификация норм публичного и частного права Индии

Индийскую правовую систему отличает свойственная странам романо-германской правовой семьи форма кодификации основных отраслей права. В сфере публичного права она выразилась в принятии уголовного, уголовнопроцессуального и гражданского процессуального кодекса. В области частного права особого внимания достойны положения Конституции 1950 года о кодификации норм частного права, а также процесс систематизации норм lex personalis представителей разных религиозных общин в Индии.

Проект ныне действующего Уголовного кодекса Индии был принят в 1860 и вступил в силу в 1862 году. В работе «Историческое введение в уголовный кодекс Индии» Н.Х. Пиллей приводит выдержки из документов индийской Комиссии по вопросам права, согласно которым при составлении кодекса она руководствовалась опытом кодификации уголовного права Франции и американского штата Лузиана. [5] Влияние упомянутых актов проявляется в схожей структуре трех кодексов. При этом культурные и исторические особенности обуславливают специфику содержания и юридической техники индийского уголовного кодекса.

До принятия действующего гражданского процессуального кодекса 1903 года на территории Индии действовали кодификационные акты, принятые в 1858 и 1877 годах. Первый уголовнопроцессуальный кодекс появился в Индии еще в 1861 году. Данный акт впоследствии дополнялся, а после был заменен ныне действующим кодексом 1973 года.

Статья 44 Конституции Республики Индия предписывает государству обеспечить принятие единого гражданского кодекса, распространяющего свое действие на всю территорию Индии. На данный момент многие институты индийского частного права регулируются актами, схожими с британскими по сфере регулирования и содержанию (Закон о договорах 1872 года, Закон о компаниях 2013 года и так далее). В наименьшей степени кодифицировано деликтное право Индии, нормы которого содержатся в многочисленных законах и судебной практике. В то же время стоит упомянуть факт принятия в 2016 году Кодекса о несостоятельности и банкротстве, распространяющего свое действие на всю территорию Индии.

Представляется, что кодификация норм частного права затрудняется отличиями в регулировании гражданско-правовых отношений обычными и религиозными нормами многочисленных общин, населяющих территорию Индии. Поэтому немаловажным представляется рассмотрение процесса кодификации норм lex personalis физических лиц в Республике Индия.

Еще до обретения Индией независимости были приняты акты, регулирующие порядок применения норм личного закона отдельных индусских общин, а также норм личного закона парсов. Впоследствии стали приниматься законы, применяемые ко всем индусам вне зависимости принадлежности к конкретной общине. Одним из первых таких актов был Закон об имущественных правах индусских женщин 1937 года. В 1947 году был подготовлен проект Кодекса индусского права, который активно обсуждался законотворческим органом Британской Индии, однако так и не был принят.

В 1954-1956 году парламентом Республики Индия был принят ряд законов, унифицировавших регулирование определенных институтов индусского права: Закон об особой форме брака 1954, Закон об индусском браке 1955 года, Закон о наследовании по индусскому праву 1956 года, Закон о несовершеннолетии и опеке в индуизме 1956 года и Закон об усыновлении и содержании ребенка 1956 года.

Наконец, в 1954 году был также принят Закон о специальных формах брака, предусматривающий режим применения религиозных норм о заключении и расторжении брака представителями всех конфессий, включая индусов, мусульман, христиан, иудеев и так далее.

Стремление к кодификации частноправовых норм с сохранением действия соответствующих основным принципам светского права норм религиозного и обычного права представителей местных общин можно считать особенностью правовой системы Индии.

(3) Возникновение $u$ развитие административного права

В индийской юридической литературе отмечается необходимость формирования и развития административного права в качестве отдельной отрасли. В научных и исследовательских работах обозначается ее предмет - распределение полномочий, обязанности, функции и 
ответственность правительственных органов, а также его основные источники - Конституция, законы и подзаконные акты. [3] В качестве основных принципов административного права выделяются верховенство права и судебный контроль деятельности администрации на основании доктрины ultra vires.

Согласно индийской учебной и научной доктрине, [3] административное право Индии включает в себя три нормативных блока: (1) полномочия и функции административных и квази-административных органов, (2) процедуры, посредством которых данные полномочия и функции осуществляются и (3) средства правовой защиты частных лиц в отношении незаконных действий и актов публичной администрации.

Выделение отраслей права на основании собственного предмета, метода и принципов свойственно континентальной правовой традиции. Следует отметить возможное заимствование индийскими юристами доктринального подхода романо-германских государств к выделению правовых отраслей.

III. Особенности применения норм индусского личного закона на территории Республики Индия

В первую очередь стоит отметить, что нормы религиозного права применяются на территории Индии только к отношениям между частными лицами. Правовое регулирование публичноправовых отношений осуществляется в Республике Индия только посредством норм светского права.

Одной из особенностей применения индусского личного закона является тот круг лиц, на который распространяются его нормы. Кодификационные акты 1954-1956 годов распространяют их действие на лиц, исповедующих любую форму индуизма, буддистов, джайнов, сикхов и любых лиц, проживающих на территории, к которой данный акт должен применяться, если такие лица не являются мусульманами, христианами, парсами или евреями по вероисповеданию или если не будет доказано, что при разрешении конкретного вопроса к данному лицу не применяются нормы индусского права. Нормы рассматриваемой правовой системы применяются также к законнорожденным и незаконнорожденным детям, если оба их родителя исповедают одну из перечисленных выше религий. Из-под действия норм индусского права изъяты лица, относящиеся к так называемым зарегистрированным кастам и племенам.

К нормам индусского личного закона относятся обычаи и традиции индусских общин. К таковым относятся правила, которые соблюдались единообразно в течение долгого времени и в связи с этим обрели силу правовой нормы среди индусов какой-либо местности, племени, общины, группы или семейства. При этом такие правила должны быть точно определены и не должны быть неразумными либо противоречащими публичному порядку. Представляется, что нормы индусского права приобрели в современной Индии статус правовых обычаев и механизм их применения совпадает с механизмом применения обычая во многих государствах.

Некоторые индусские обычаи были упразднены специальными законами или судебными решениями. Например, практика самосожжения вдовы индуса (sati), была упразднена британским законом 1829 года, а тамильский обряд thalaikoothal (принудительная эвтаназия в отношении пожилых людей), был признан Верховным судом в решении по делу Aruna Ramchandra Shanbaug v. Union of India 2011 года противоречащим положениям статьи 21 Конституции Индии о праве на жизнь.

Примечательной особенностью применения религиозных норм в Республике Индия является то, что закон уполномочивает на их применение светские суды, в компетенцию которых входит разрешение гражданско-правовых споров, вплоть до Верховного суда Союза.

Выявленные особенности применения норм индусского права на территории Индии представляют интерес как для целей исследования правовых систем стран Южной Азии, так и для целей изучения проблематики применения религиозных норм в современных светских правовых системах.

IV. Особенности применения мусульманского личного закона на территории Республики Индия

Применение индийскими судами норм более чем одной религиозной системы права само по себе примечательно. Правовым основанием применения на территории Индии норм мусульманского права является принятый в 1937 году Закон о применении мусульманского личного закона (шариата). Согласно статье 2 данного акта в отсутствие обычая или традиции, состоящей в ином, мусульманский личный закон (шариат) применяется к отношениям, связанным с наследованием по закону, имущественными правами лиц женского пола, а также к любым иным отношениям, регулируемым личным законом, например к брачным отношениям и различным видам расторжения брака.

При этом нормы шариата применяются в том случае, если лицо заявит перед органом государственной власти о подчинении правоотношения религиозным нормам. Такое заявление может сделать лицо, которое является мусульманином, обладает дееспособностью на заключение договоров по смыслу индийского Закона о договорах 1872 года, а также проживает на территории, на которую распространяет действие акт 1937 года. Законом предусмотрена процедура обжалования отказа в применении к лицу норм мусульманского личного закона.

В целях уточнения некоторых вопросов, связанных с рассмотрением исков о расторжении брака по инициативе супруги в соответствии с нормами шариата, в 1939 году был принят Закон о расторжении мусульманского брака.

При применении норм шариата индийские суды не просто проверяют их соответствие нормам светского права, но и исследуют соответствие 
отдельных практик основным принципам мусульманского личного закона. Так, в 2002 году в Верховный суд Индии при рассмотрении вопроса о конституционности тройного талака в деле Shamim Ara vs State Of U.P, опирался на толкование норм шариата о данном виде расторжения брака индийскими судами, а также выдающимися представителями доктрины мусульманского права. По результатам рассмотрения спора Верховный суд признал тройной талак неконституционной практикой, отметив также его несоответствие принципам шариата.

V. Применение иных религиозных норм и норм обычного права в Республике Индия

В качестве личного закона физических лиц на территории Индии применяются не только нормы мусульманского и индусского права, но и иные религиозные и обычные нормы, регулирующие правовой статус лиц, принадлежащих к разным общинам, в частноправовых отношениях. В этой связи стоит рассмотреть (1) особенности применения норм личного закона парсов и христиан и (2) вопрос правового режима защиты лиц от кастовой дискриминации.

(1) Религиозные нормы, применяемые в качестве личного закона парсов и христиан

Личный закон парсов применяется в Индии специализированными судами еще с XIX века. В современной Индии сохраняет силу Закон о заключении и расторжении брака парсами 1936 года, в соответствии с которым учреждаются специализированные матримониальные суды, в компетенцию которых входит разрешение споров из брачных отношений парсов. Это единственные суды, в которых в рассмотрении дела по существу могут участвовать присяжные заседатели.

Также на территории Индии действует специальный Закон о христианском браке 1872 года, устанавливающий порядок заключения и расторжения христианского церковного брака. Данный закон распространяет действие на последователей различных ответвлений христианства. В научной литературе отмечается, что при применении норм данного акта суды часто прибегают к правовым фикциям и иным приемам юридической техники с целью облегчения применения этого весьма архаичного закона. [4, с. 271-272]

(2) Правовой режим защчитыл лиц от кастовой дискриминации в Индии

По данным неправительственных организаций, кастовая дискриминация, хотя исторически и была обусловлена системой индусских религиозных воззрений, на сегодняшний день проявляется среди представителей разных конфессий. Она представляет собой социальное, а не исключительно религиозное явление, поэтому представляется, что противодействуя дискриминации по кастовому признаку, индийский законодатель стремится исключить применение обычных, а не религиозных норм.
Правовой механизм борьбы с кастовым неравенством на территории Республики Индия основывается на конституционных нормах, касающихся упразднения неприкасаемости, недопущения дискриминации по кастовому признаку, а также позитивной дискриминации в отношении так называемых далитов. Приложения к основному закону содержат списки зарегистрированных каст и племен, на которые распространяется закрепленный в Конституции режим. В целях исполнения конституционных норм об обеспечении кастового равенства в Индии были приняты специальные законы и многочисленные указы Президента Республики.

В 1989 году был принят специальный Закон о предупреждении злодеяний в отношении зарегистрированных каст и зарегистрированных племен, а также учреждены специализированные судебные органы для рассмотрения дел о кастовой дискриминации. Толкование норм о запрете кастовой дискриминации индийскими судебными органами привело к закреплению дополнительных гарантий прав представителей различных каст.

Несмотря на определенные трудности, с которыми сталкиваются органы публичной администрации и частные лица в ходе практического применения правового механизма борьбы с кастовым неравенством, опыт подобного регулирования общественных отношений представляется достойной рассмотрения чертой индийской правовой системы.

Заключение

Квалификация правовой системы Республики Индия в качестве смешанной не вызывает сомнений. Хотя индийский правопорядок основывается на принципах англосаксонского права, он проявляет черты, свойственные континентальным правовым системам, а также допускает регулирование отношений между частными лицами нормами lex personalis представителей разных религиозных течений.

В той степени, в которой в индийской правовой системе имеет место проявление черт различных правовых семей или систем, такое проявление характеризуется национальными особенностями. К таковым можно отнести ограничение сферы применения заимствованных правовых принципов, особый подход к систематизации права, сочетание религиозных и светских норм, особые правовые институты и конструкции и другие.

Дальнейшее изучение особенностей правовой системы Индии может способствовать формированию достоверного знания о юридической географии мира, о смешанных правовых системах, а также о совместимости и взаимодействии различных источников права, правовых доктрин и правоприменительных практик на фоне общей тенденции к взаимной интеграции правопорядков различных государств. 
Список литературы:

[1] Deshpande V. S. Nature of the Indian Legal System //The Indian Legal System; 1978: 1-17.

[2] Laxmikanth M. Indian polity // McGraw-Hill Education; 2016.

[3] Massey I.P. Administrative law // Eastern Book Company; 2008.

[4] Master M. Personal laws of religious communities in India. Parsi Zoroastrian, Christian, Muslim, Hindu, and Jewish; 1986.
[5] Pillai K. N., Aquil S. Essays on the Indian Penal Code // Indian Law Institute, New Delhi; 2015.

[6] Ramakrishnan V. Guide to Indian Laws; 2001.

[7] Singh M. P., Kumar N. (ed.). The Indian yearbook of comparative law 2016 // Oxford University Press; 2017.

[8] Sharma K. M. Civil Law in India //Wash. ULQ; 1969.

УДК - 340.5:347.73

ГРНТИ 10.21.91

«РАЗРЕШЕНИЕ НАЛОГОВЫХ СПОРОВ В СОЕДИНЁННЫХ ШТАТАХ АМЕРИКИ»

DOI: $10.31618 /$ ESU.2413-9335.2020.6.70.561

Чертков Николай Николаевич

Студент

Токарева Оксана Степановна Дочент кафедры

международного права и сравнительного правоведения

Юридического института

Иркутского Государственного Университета

\title{
"RESOLVING OF TAX CONTROVERSY IN THE UNITED STATES OF AMERICA"
}

\author{
Chertkov Nikolai Nicolaevich \\ Student \\ Tokareva Oksana Stepanovna \\ Cand. Philol. Sciences, ass. professor \\ Department of International Law and Comparative Legal Study \\ Law Institute, Irkutsk state University
}

\section{АННОТАЦИЯ}

В статье рассматривается Налоговый суд США, история его возникновения, юрисдикция, судьи, представительство сторон, генезис налогового судебного спора, порядок рассмотрения дел, положение Налогового Суда в системе административной юстиции США, разрешение налоговых споров РФ и США.

\section{ABSTRACT}

The article deals with the comparative study of the structure and status of the US Tax Court and the Russian Federation court system in resolving of tax controversy. The authors focus on the description of jurisdiction, functions of judges, proxyship of parties in controversy, genesis of tax controversy and order of proceedings. Special emphases are given to the defining of the status of the US Tax Court in the system of the US Administrative justice and ways of resolving of tax disputes in the Russian Federation and the USA.

Ключевые слова: Налоговый суд США, юрисдикция налогового суда, судьи, генезис налогового судебного спора, сравнительно-правовой анализ судебной системы РФ и США в решении налоговых споров.

Keywords: The US Tax Court, jurisdiction of the US Tax Court, judges, genesis of tax controversy, ratherlegal analysis of the Russian Federation US court system in resolving tax controversy.

Общепризнанным можно считать тот факт, что в обеспечении института прав человека органы государственной власти играют значительную роль. Эти институты созданы не только с целью обеспечения необходимых условий для защиты прав человека, но также призваны выполнять реальную функцию защиты этих прав и свобод. Органы налогового контроля не являются исключением из правил. Проблема обеспечения соблюдения порядка правовых норм в сфере налоговых отношений является одной из самых важных задач, которые ставятся перед органами власти любого государства.
Как показывает судебная практика, взаимоотношения между налогоплательщиками и налоговыми органами, независимо от устройства налоговой и судебной системы конкретного государства, как правило, имеют конфликтный характер. Это объясняется, прежде всего, наличием объективных противоречий, появляющихся между финансовыми интересами физических лиц и организаций с одной стороны, и государственными структурами - с другой. В тех случаях, когда сторонам конфликта не удается прийти к единому мнению, а досудебные способы урегулирования налоговых споров исчерпаны, для защиты своих 